\title{
Determination of U, S, V, Cu, Zn, Sr, Mo, and Ce in Carbonate Rocks by Wavelength Dispersive X-Ray Fluorescence Spectrometry and Inductively Coupled Plasma Optical Emission Spectrometry
}

\author{
Chanchal Sarbajna*, Smeer Durani, S. Nayak, M. Krishnakumar, V. M. Karuppan, and K. Shivkumar \\ Atomic Minerals Directorate for Exploration and Research, \\ Department of Atomic Energy, Hyderabad, India-500016
}

\begin{abstract}
The paper describes a simple, rapid, accurate, and cost-effective wavelength dispersive $\mathrm{x}$-ray fluorescence spectrometry (WDXRFS) methodology as an alternate to complimentary techniques such as fluorimetry and inductively coupled plasma optical emission spectrometry (ICPOES) for the determination of $\mathrm{U}$, $\mathrm{S}, \mathrm{V}, \mathrm{Cu}, \mathrm{Zn}, \mathrm{Sr}, \mathrm{Mo}$, and $\mathrm{Ce}$ in carbonate rocks. The WDXRF spectrometer is calibrated using three matrix matching international certified reference materials (CRMs) of LKSD-1, LKSD-2, and LKSD-3 Carbonate Lake Sediment, alonh with a few in-house standards. The $S \mathrm{~K}_{\alpha}, \mathrm{V} \mathrm{K}_{\alpha}, \mathrm{Zn} \mathrm{K}_{\alpha}$, $\mathrm{Cu} \mathrm{K}{ }_{\alpha}, \operatorname{Sr~K}_{\alpha}$, Mo K $\mathrm{K}_{\alpha}$, Ce $\mathrm{L}_{\alpha}$, and $\mathrm{U}-\mathrm{L}_{\alpha}$ lines were considered for quantifying the elements. The LKSD-1 CRM was also used as the test sample to validate the analytical methodology.
\end{abstract}

By using WDXRFS, accuracies of better than $4 \%$ were achieved, except for $U(7.2 \%$ at $10 \mathrm{ppm})$ and Mo (10\%, at $10 \mathrm{ppm})$. For ICP-OES it was better than $5 \%$, except for Mo (10.0\%, at $10 \mathrm{ppm})$ and $\mathrm{Ce}(11.1 \%$, at $10 \mathrm{ppm})$. The precision for WDXRFS was better than 3\%, except for Mo $(3.7 \%$, at $10 \mathrm{ppm})$ and $\mathrm{U}(5.2 \%$, at $10 \mathrm{ppm}$ ); for ICP-OES it was better than 5\%, except for Mo (14.2\%, at $10 \mathrm{ppm})$, Ce (6.2\%, at $10 \mathrm{ppm})$, and $\mathrm{U}(8.5 \%$, at $10 \mathrm{ppm})$. The limits of detection (LODs) were also calculated for both techniques. The accuracy, precision, and LODs obtained show the viability of this simple, non-destructive, and rapid WDXRFS methodology as an alternate to complimentary wet chemical techniques for the determination of the above-mentioned elements in carbonate rocks.

\section{INTRODUCTION}

The rapid, cost-effective, precise, and accurate determination of uranium and some other trace elements in different kinds of geological materials is very significant at almost every stage of exploration from orientation, reconnaissance, and semi-detailed surveys to exploitation of the desired mineral. These data are required for evaluation of the geological terrain to narrow down the target, geo-modeling, assessment of grade, tonnage, etc. Uranium is associated along with

*Corresponding autbor.

E-mail: csarbajna@gmail.com sulfide-bearing minerals like pyrite $\left(\mathrm{FeS}_{2}\right)$, chalcopyrite $\left(\mathrm{CuFeS}_{2}\right)$, and molybdenite $\left(\mathrm{MoS}_{2}\right)$, etc., within the host carbonate rocks (dolostones) found near Tumallapalle, Cuddapah district, Andhra Pradesh, India (1). Hence, analysis of elemental sulfur in sulfide-bearing carbonate rocks plays a major role in identifying the type and nature of mineralization. The Atomic Minerals Directorate for Exploration and Research (AMD) has identified unique types of uranium deposits hosted in carbonate rock (dolostone) near Tumalapalle (2) and in brecciated limestone near Gogi, Gulbarga district, Karnataka, India (3).
A large number of carbonate rock samples from Tumalapalle have been analyzed for uranium and other trace elements. Wavelength dispersive X-ray fluorescence spectrometry (WDXRFS) is thought to be the right choice of methodology for the rapid analysis of large numbers of samples. However, matrix matching reference standards need to be prepared inhouse for calibration of WDXRFS since CRMs rich in carbonate-containing trace elements, including uranium, are not available. The complimentary techniques of ICPOES and fluorimetry have been used for the preparation of in-house standards of carbonate rocks from the Tumallapalle area along with three international CRMs for the calibration and quantitative estimation of trace elements, including uranium and sulfur.

WDXRFS is a suitable nondestructive method for the rapid determination of a wide range of concentrations (ppm to \%) of different elements in geological materials such as rocks, minerals, and ores, and is regarded as one of the most important analytical tool for the geochemical determination of major, minor, and selected trace elements $(4,5)$. WDXRFS analysis produces results with high precision using a simple and rapid sample preparation method involving finely ground $(-200$ mesh or $<63$ micron) powdered pellets. However, the use of WDXRFS requires many matrix matching standard samples for reference and calibration. The determination of different components, such as sulfur in silicate and carbonate rocks by XRF 
using the fusion bead sample preparation method, was reported by Milada (6).

In the present study, a powder pelletization sample preparation technique was used for the determination of sulfur along with $\mathrm{U}, \mathrm{V}$, $\mathrm{Cu}, \mathrm{Zn}, \mathrm{Sr}, \mathrm{Mo}$, and $\mathrm{Ce}$ in carbonate rocks. The powder pelletization sample preparation technique has several advantages over the fusion bead method since it is simple, fast, inexpensive, and non-destructive, the chances of sample dilution is minimal and provides quick feedback to the exploration program (7-9) .

Various methods such as gamma ray spectrometry, fluorimetry, atomic absorption spectrometry (AAS), inductively coupled plasma optical emission spectrometry (ICPOES), inductively coupled plasma mass spectrometry (ICP-MS), and WDXRFS are used for the determination of uranium in geological samples. Fluorimetric determination of trace level uranium is a popular technique due to its high sensitivity and specificity and is widely used for the analysis of a variety of geological material (1011). The majority of reported works deal with the determination of uranium in different rocks after selective separation of uranium because many elements quench fluorescence (12). Therefore, separation and pre-concentration of uranium is required for its determination by fluorimetry in a complex matrix. Further AAS, ICP-OES, and ICP-MS are mostly used for the determination of trace elements such as $\mathrm{V}, \mathrm{Cu}, \mathrm{Zn}, \mathrm{Sr}$, Mo, Ce, and $\mathrm{S}$ and require sample dissolution in aqueous/acid media (13).

The present study aims at developing an alternate rapid, simple, accurate, and precise methodology for the characterization of different types of carbonate rocks by WDXRFS, while validating the obtained data by fluorimetry for uranium and by ICP-OES for other trace elements. The accuracy, precision, and limits of detection achieved for $\mathrm{U}, \mathrm{V}, \mathrm{Cu}, \mathrm{Zn}, \mathrm{Sr}, \mathrm{Mo}$, $\mathrm{Ce}$, and $\mathrm{S}$ are well documented and are comparable with ICP-OES. These samples were then used as internal reference standards for calibration of the WDXRFS prior to their analysis.

\section{EXPERIMENTAL}

\section{Instrumentation}

WDXRFS

A sequential wavelength dispersive $\mathrm{X}$-ray fluorescence spectrometer Model MagiX-PRO: PW2440 (PAnalytical, Netherlands), equipped with an end window Rh anode, having a rated capacity of $4 \mathrm{~kW}(60 \mathrm{kV} / 125 \mathrm{~mA})$ instrument and a $4 \mathrm{~kW}$ rhodium end window $\mathrm{x}$-ray tube, was used in this study. The instrumental parameters such as spectral lines, analyzing crystals, collimators, detectors, peak and background positions, voltage $(\mathrm{kV})$, current $(\mathrm{mA})$, and counting times are listed in Table I.

\section{ICP-OES}

A Model ULTIMA-2 inductively coupled plasma optical emission spectrometer (Horiba Jobin Yvon, France), was used for this study. The instrumental specifications/ parameters and operating conditions are listed in Table II.

\section{Pellet Fluorimeter}

An ECIL filter fluorimeter (Electronic Corporation of India Limited, India), having an excitation light source (Hg vapor lamp) wavelength of $365 \mathrm{~nm}$ and equipped with a PMT detector arranged at zero

TABLE I

Instrumental Parameters for WDXRFS Using $4 \mathrm{~kW}$ End Window Rh Tube

\begin{tabular}{|c|c|c|c|c|c|c|c|c|c|c|c|}
\hline Element & & $\theta$ Position & & Coun & ing tim & (sec.) & & & & & \\
\hline $\begin{array}{l}\text { X-ray } \\
\text { Line }\end{array}$ & Peak & Bg 1 & Bg 2 & Peak & Bg 1 & Bg 2 & $\begin{array}{c}\text { Analyzing } \\
\text { Crystal }\end{array}$ & Detector $^{\mathrm{a}}$ & Collimator & $\mathrm{kV}$ & $\mathrm{mA}$ \\
\hline $\mathrm{SK}_{\alpha}$ & 110.7208 & -0.7126 & 1.2358 & 120 & 10 & 10 & Ge 111 & GFPC & $300 \mu \mathrm{m}$ & 30 & 100 \\
\hline $\mathrm{VK}_{\alpha}$ & 69.3200 & -0.0402 & - & 120 & 20 & - & LiF 220 & GFPC & $300 \mu \mathrm{m}$ & 60 & 50 \\
\hline $\mathrm{CuK}_{\alpha}$ & 65.5316 & 0.148 & - & 60 & 10 & - & $\mathrm{LiF} 220$ & Duplex & $150 \mu \mathrm{m}$ & 60 & 50 \\
\hline $\mathrm{ZnK}_{\alpha}$ & 60.5262 & -0.459 & - & 30 & 10 & - & LiF 220 & SC & $150 \mu \mathrm{m}$ & 60 & 50 \\
\hline $\operatorname{SrK}_{\alpha}$ & 25.1086 & 0.4338 & - & 30 & 10 & - & LiF 220 & SC & $150 \mu \mathrm{m}$ & 60 & 50 \\
\hline $\operatorname{MoK}_{\alpha}$ & 28.8490 & 0.3918 & - & 120 & 10 & - & LiF 220 & SC & $150 \mu \mathrm{m}$ & 60 & 50 \\
\hline $\mathrm{CeL}_{\alpha}$ & 79.1714 & -0.5574 & - & 60 & 10 & - & LiF 200 & Duplex & $300 \mu \mathrm{m}$ & 60 & 50 \\
\hline $\mathrm{U}-\mathrm{L}_{\alpha}$ & 37.2578 & -0.3348 & 0.4508 & 120 & 10 & 10 & LiF 220 & SC & $300 \mu \mathrm{m}$ & 60 & 50 \\
\hline
\end{tabular}

${ }^{\mathrm{a}} \mathrm{GFPC}=$ Gas flow proportional counter.

$S C=S$ cintillation counter.

Duplex $=$ Gas flow proportional counter and sealed xenon detector. 
angle geometry, was used for the uranium fluorescence intensity measurements. A characteristic uranium fluorescence of $555 \mathrm{~nm}$ emanating from the sample pellet was measured.

\section{Sample Preparation \\ WDXRFS}

An amount of 200-300 g (3-4 inches) of sample was crushed to $4-6$ mesh size by a jaw crusher, then a 10-g sample was taken and further ground to -200 mesh using a laboratory-type disc mill and the powders were homogenized. Smaller representative volumes of the homogenized powders were obtained by coning and quartering. The powdered samples ( $1 \mathrm{~g}$ ) were spread uniformly over a 20 -g boric acid bed in a cylindrical sample die, and finally pelletized in a semi-automatic pelletizer at a pressure of $20,000 \mathrm{~kg} / \mathrm{cm}^{2}$ resulting in a solid pellet of $41 \mathrm{~mm}$ in diameter. Thus, flat and homogeneous pellets of both the sample and the CRMs were obtained (4).

\section{ICP-OES}

The powdered sample (0.5 g) was transferred into a platinum dish and incinerated in a furnace at $650{ }^{\circ} \mathrm{C}$ for one hour to remove any organic matter. Then, it was treated with $5 \mathrm{~mL}$ of $40 \% \mathrm{HF}$ and $2 \mathrm{~mL}$ of concentrated $\mathrm{HNO}_{3}$ and evaporated to dryness in a boiling water bath. The process was repeated three times with $3 \mathrm{~mL}$ of $\mathrm{HF}$ and $2 \mathrm{~mL}$ of $\mathrm{HNO}_{3}$. The sample was then treated three times with $\mathrm{HNO}_{3}$. The residue was dissolved in $\mathrm{HNO}_{3}$ solution and made up to $100 \mathrm{~mL}$ volume maintaining a final acidity of $2 \%(10,12)$. However, the solutions for the determination of sulfur were prepared by fusion of the samples with sodium peroxide.

\section{Pellet Fluorimetry}

The powdered rock sample (1.0 g) was treated with $3 \mathrm{~mL} \mathrm{HF}$ and $5 \mathrm{~mL} \mathrm{HNO}_{3}$ three times and digested with $10 \% \mathrm{HNO}_{3}$ in a platinum crucible. Uranium was extracted with ethyl acetate using aluminium nitrate as the salting out agent. The aliquot from the organic layer to be analyzed was dried under an infrared lamp, combined with a flux $\left(\mathrm{Na}_{2} \mathrm{CO}_{3}: \mathrm{NaF}=4: 1\right)$ in

TABLE II Instrumental Specifications and Operating Conditions of ICP-OES

Parameters

Model

Mounting

Focal Length

Grating grooves

Order of measurement

1st Order resolution

Type of RF Generator

Observation

Frequency of Generator

Generator power

Plasma flow rare

Sheath gas flow rate

Nebulizer gas flow rate

Sample uptake

Type of spray chamber
Horiba Jobin Yvon ULTIMA-2

Czerny - Turner

One meter

$4320 \mathrm{~g} / \mathrm{mm}, 2400 \mathrm{gr} / \mathrm{mm}$

$1^{\text {st }}$ order

$0.005 \mathrm{~nm}$

Solid state generator

Radial viewing

$40.68 \mathrm{MHz}$

$1200 \mathrm{~W}$

$12 \mathrm{~L} / \mathrm{min}$

$0.2 \mathrm{~L} / \mathrm{min}$

$0.68 \mathrm{~L} / \mathrm{min}$

Meinhard Nebulizer

Cyclonic

\section{Atomic Apectroscopy

a platinum planchet, and heated to approximately $850^{\circ} \mathrm{C}$. After cooling, the fused pellet was used for intensity measurements in the filter fluorimeter.

\section{METHODOLOGY}

\section{WDXRFS}

\section{Calibration Standards}

The instrument was calibrated using the three international CRMs LKSD-1, 2, and 3 Carbonate Lake Sediment (Canada Centre for Energy and Mineral Technology, (CANMET), Canada) (13) and inhouse reference standards prepared from carbonate rock samples (from the proposed uranium mining project, Tumallapalle, Cuddapah district, A.P., India). These samples were analyzed several times for $\mathrm{V}$, $\mathrm{Cu}, \mathrm{Zn}, \mathrm{Sr}, \mathrm{Mo}, \mathrm{Ce}$, and $\mathrm{S}$ by ICPOES and AAS and for uranium by fluorimetry. The in-house standards, having similar matrices, helped to analyze the unknown samples with lower concentrations of these metals. Calibration was made using corrected net peak intensity (K counts/s) against concentration. The calibration graphs for determining $\mathrm{U}, \mathrm{S}, \mathrm{V}, \mathrm{Cu}, \mathrm{Zn}, \mathrm{Sr}$, Mo, and Ce in carbonate rocks by WDXRFS are given in Figure 1 (A-H).

\section{Correction for Spectral Overlap}

Pure elements were used to determine the degree of spectral line overlap and for calculation of the corrections. The net intensity (Rji) of the interfering element (j) was measured at the 2 theta angle for the element (i) to be determined. Then the net intensity of a noninterference line $(\mathrm{Rj})$ of the interfering element ( $j$ ) was measured. The ratio of $\mathrm{Rji} / \mathrm{Rj}$ was taken as line overlap correction factor. Suitable software "Super Q, 4.0D version" (PANalytical B.V., Almelo, The Netherlands) was used to take care of dead time correction and interelement matrix effects. 

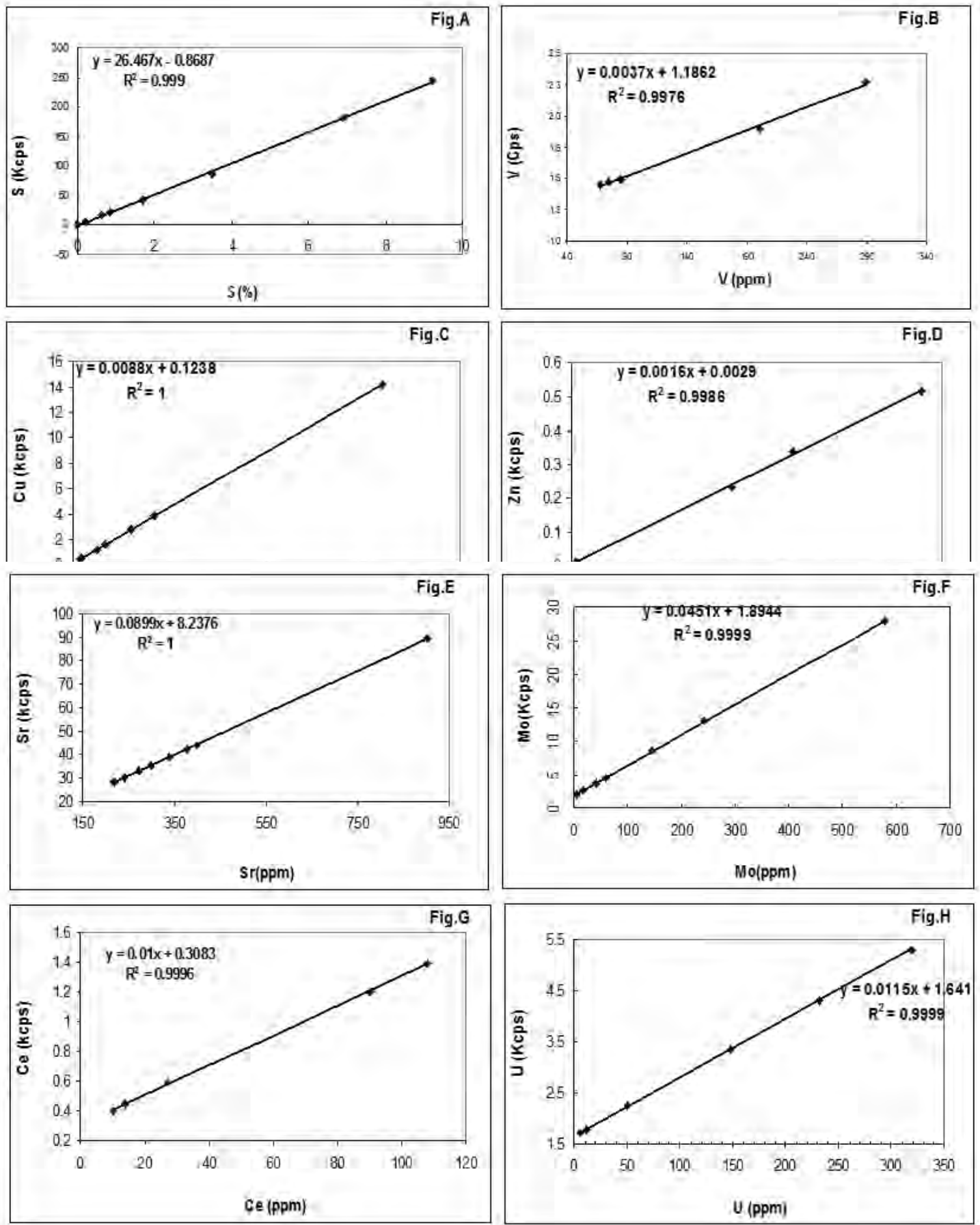

Fig. 1. Calibration curves of $S, \mathrm{~V}, \mathrm{Cu}, \mathrm{Zn}, \mathrm{Sr}, \mathrm{Mo}, \mathrm{Ce}$, and $\mathrm{U}$ drawn by using different international and in-house standards for DXRFS. 
The $\mathrm{UL}_{\alpha}, \mathrm{SK}_{\alpha}, \mathrm{VK}_{\alpha}, \mathrm{CuK}_{\alpha}$, $\mathrm{ZnK}_{\alpha}, \mathrm{SrK}_{\alpha}, \mathrm{MoK}_{\alpha}$, and $\mathrm{CeL}_{\alpha}$ lines, considered to quantify these elements in carbonate rocks as the concentration of the adjacent interfering elements, are much less in the present matrix (Table I). The energy of $\mathrm{UK}_{\alpha}$ and $\mathrm{CeK}_{\alpha}$ was 97.131 and $34.566 \mathrm{KeV}$, respectively. When the excitation is done by continuum source alone, the voltage should be such that the tube voltage is at least 3-4 times the excitation potential of the analyte element. In the present study, the instrument used was $60 \mathrm{kV}$ (maximum) which does not permit excitation of $\mathrm{UK}_{\alpha}$ and $\mathrm{CeK}_{\alpha}$ and, instead, L lines were selected to determine both elements.

\section{ICP-OES/Pellet Fluorimeter}

All dilutions were performed using Milli-Q ${ }^{\mathrm{TM}}$ water (MilliporepCorporation, USA). SupraPur ${ }^{\circledR}$ 40\% HF (E. Merck, Germany) and subboiled $\mathrm{HCl}$ and $\mathrm{HNO}_{3}$, GR grade (Merck, Germany), were used. The trace element stock solutions were prepared from high purity oxides $(99.99 \%$ or $99.999 \%$, Alfa Aesar, U.K) by dissolution in $\mathrm{HCl}$. Uranium stock solution was prepared from uranium nitrate salt (AnalR ${ }^{\circledR}$ grade). First, singleelement $(1000 \mu \mathrm{g} / \mathrm{mL})$ stock solutions were prepared, and a mixed multi-element standard solution $(10 \mu \mathrm{g} / \mathrm{mL})$ was prepared from the above stock solution by appropriate dilution. Solutions of the CRMs LKSD 1, 2, and 3 were prepared and analyzed.

In ICP-OES, the sample is nebulized and transferred to the argon plasma, decomposed, atomized, and ionized whereby the atoms and ions are excited. Each element emits light at characteristic wavelengths, and these lines can be used for quantitative analysis after a calibration. The light emitted by the plasma contains numerous argon lines and a continuum that extends over the complete wavelength range. These emissions originate from recombination of the Ar ions, electrons, and Bremsstrahlung of the electrons. The matrix can vary the background intensity and its level is measured and corrected. The background correction is applied on both sides of the peak. The background correction points, wavelengths, detection limits (DLs), and background equivalent concentration (BEC) for each element are provided in Table III.

It was observed that during acid digestion of the carbonate rock samples, large quantities of highpurity acids are consumed and quick effervescence may cause some loss due to sputtering. Since these samples contain high amounts of calcium, formation of refractory $\mathrm{CaF}_{2}$ poses difficulty in

\section{Atomic Apectroscopy Vol. 34(1), Jan./Feb. 2013}

dissolution with $\_3 \% \mathrm{HNO}_{3}$. A high calcium content in the sample is known to cause signal suppression during ICP-OES analysis as it cools down the plasma. To overcome these problems, the samples were digested in closed containers in order to avoid sputtering during acid digestion of the high carbonate rock samples. In order to avoid possible formation of $\mathrm{CaF}_{2}$, the samples were pretreated with $5 \%(\mathrm{v} / \mathrm{v})$ $\mathrm{HNO}_{3}$, filtered, and further processed with $\mathrm{HF}$ and $\mathrm{HNO}_{3}$. In order to do away with the signal depression due to the high Ca content, a higher RF power of $1200 \mathrm{~W}$ was applied during sample analysis. The determination of total sulfur by chemical means is cumbersome. Since the samples were digested with highly corrosive aqua regia, later dissolved in nitric acid, and finally determined by ICP-OES, the optics have to be purged with nitrogen for 3 hours prior to analysis. Sulfur can also be determined by conventional barium sulfate precipitation after fusion with sodium peroxide and water leaching of the fused melt. Excess barium is determined by titration with EDTA (15) or can also be determined by AAS.

\section{RESULTS AND DISCUSSION}

The carbonate rock samples, along with CRM LKSD-1, were chemically characterized by AAS, ICP-OES, and fluorimetry. The

TABLE III

Wavelength, Background Correction, and Analytical Conditions for ICP-OES

\begin{tabular}{|c|c|c|c|c|c|c|c|c|c|c|c|c|c|}
\hline $\begin{array}{l}\text { Ele- } \\
\text { ment }\end{array}$ & $\begin{array}{l}\text { Wavelength } \\
\text { (nm) }\end{array}$ & $\begin{array}{c}\mathrm{BEC} \\
(\mu \mathrm{g} / \mathrm{L})\end{array}$ & $\begin{array}{c}\mathrm{DL} \\
(\mu \mathrm{g} / \mathrm{L})\end{array}$ & BGC & \multicolumn{2}{|c|}{$\begin{array}{c}\text { Standard } \\
(\mu \mathrm{g} / \mathrm{L})\end{array}$} & Gain & $\begin{array}{c}\text { High } \\
\text { Voltage }\end{array}$ & MP & $\mathrm{CP}$ & IT & $\begin{array}{l}\text { Exit } \\
\text { slit }(\mu \mathrm{m})\end{array}$ & $\begin{array}{l}\text { Analysis } \\
\text { Mode }\end{array}$ \\
\hline S & 181.978 & 0.57 & 0.17 & \pm 0.016 & 10 & 1.0 & 100 & 990 & 9 & 5 & 0.5 & 15 & Gauss \\
\hline $\mathrm{Ce}$ & 418.660 & 0.128 & 0.95 & \pm 0.015 & 10 & 1.0 & 100 & 710 & 9 & 5 & 0.5 & 15 & Gauss \\
\hline $\mathrm{Cu}$ & 324.754 & 0.10 & 3.0 & +0.016 & 1.0 & 0.1 & 100 & 700 & 9 & 5 & 0.5 & 15 & Gauss \\
\hline Mo & 202.030 & 0.05 & 1.5 & -0.009 & 1.0 & 0.1 & 10 & 800 & 9 & 5 & 0.5 & 15 & Gauss \\
\hline $\mathrm{Sr}$ & 407.771 & 0.05 & 1.5 & -0.012 & 1.0 & 0.1 & 10 & 630 & 9 & 5 & 0.5 & 15 & Gauss \\
\hline V & 292.402 & 0.09 & 2.7 & -0.016 & 1.0 & 0.1 & 100 & 590 & 9 & 5 & 0.5 & 15 & Gauss \\
\hline $\mathrm{Zn}$ & 213.856 & 0.02 & 0.6 & -0.013 & 1.0 & 0.1 & 100 & 590 & 9 & 5 & 0.5 & 15 & Gauss \\
\hline
\end{tabular}

BEC: Background equivalent concentration, BGC: Background Correction, DL: Detection limit; BEC x RSD (1\%) $\mathrm{x}$ 3,

MP: Measurement point, CP: Calculated Points, IT: Integration Time (s) 
values were obtained with sufficient statistical analysis of the analytical data generated. The certified values of $\mathrm{U}, \mathrm{S}, \mathrm{V}, \mathrm{Cu}, \mathrm{Zn}, \mathrm{Sr}, \mathrm{Mo}$, and $\mathrm{Ce}$ in the international standard LKSD-1 and the statistically arrived values in one in-house reference material (FC-155/S-2354) are listed in Table IV. The values obtained by ICP-OES and WDXRFS were in close agreement.

The accuracies achieved (Table V) by WDXRFS were as follows: $\mathrm{U}: \pm 7.22 \%, \mathrm{~S}: \pm 0.64 \%, \mathrm{~V}: \pm 1.15 \%$, Cu: $\pm 2.27 \%, \mathrm{Zn}: \pm 0.30 \%$, Sr: $\pm 2.40 \%$, Mo: $\pm 10.0 \%$, and Ce: $\pm 3.70 \%$. The accuracies achieved by ICP-OES were: S: $\pm 1.91 \%, \mathrm{~V}: \pm 4.60 \%$, Cu: $\pm 4.55 \%, \mathrm{Zn}: \pm 3.93 \%$, Sr: $\pm 2.80 \%$, Mo: $\pm 10.0 \%$, and Ce: $\pm 11.11 \%$, which is comparable with their recommended values. The accuracy and precision achieved by the fluorimetry technique for $\mathrm{U}$ were $\pm 1.03 \%$ and $8.54 \%$, respectively.

The precision of the instrument was evaluated by six replicate analyses of the international standard reference material LKSD-1. The average concentrations and the \%RSDs (coefficient of variation) are listed in Table V. It can be seen that the \%RSDs for the elements determined by WDXRFS were as

TABLE IV

Comparison of Analytical Values of

Certified International Standard LKSD-1 and In-house Standard FC-155 (S-2354) by WDXRFS, ICP-OES, and Fluorimetry Techniques

\begin{tabular}{|c|c|c|c|c|c|c|c|}
\hline \multirow[t]{2}{*}{ Element } & \multicolumn{3}{|c|}{ LKSD-1 } & \multirow{2}{*}{ Element } & \multicolumn{3}{|c|}{ FC-155 (S-2354) } \\
\hline & $\begin{array}{l}\text { Certif. } \\
\text { Value }^{\mathrm{a}}\end{array}$ & WDXRFS & $\begin{array}{l}\text { ICP- } \\
\text { OES }\end{array}$ & & $\begin{array}{l}\text { Assigned } \\
\text { Value }\end{array}$ & WDXRFS & $\begin{array}{l}\text { ICP- } \\
\text { OES }\end{array}$ \\
\hline S (\%) & 1.57 & 1.56 & 1.54 & S (\%) & 0.85 & 0.83 & 0.83 \\
\hline $\mathrm{V}(\mathrm{ppm})$ & 87 & 86 & 83 & $\mathrm{~V}(\mathrm{ppm})$ & 170 & 168 & 165 \\
\hline $\mathrm{Cu}(\mathrm{ppm})$ & 44 & 43 & 42 & $\mathrm{Cu}(\mathrm{ppm})$ & 135 & 132 & 132 \\
\hline $\mathrm{Zn}(\mathrm{ppm})$ & 331 & 330 & 318 & $\mathrm{Zn}(\mathrm{ppm})$ & 5 & 6 & 5 \\
\hline $\mathrm{Sr}(\mathrm{ppm})$ & 250 & 256 & 243 & $\mathrm{Sr}(\mathrm{ppm})$ & 556 & 566 & 548 \\
\hline Mo (ppm) & 10 & 11 & 9 & Mo (ppm) & 1) 210 & 210 & 205 \\
\hline Ce (ppm) & 27 & 26 & 24 & Ce (ppm) & 10 & 11 & 10 \\
\hline $\mathrm{U}^{\mathrm{b}}(\mathrm{ppm})$ & 9.7 & 9 & 9.8 & $\mathrm{U}^{\mathrm{b}}(\mathrm{ppm})$ & 48 & 49 & 46 \\
\hline
\end{tabular}

${ }^{a}$ Certified Value, Govindaraju, 1996.

b Fluorimetry.

TABLE V

Accuracy and Precision Achieved for International Standard Sample (LKSD-1) by WDXRFS and ICP-OES

\begin{tabular}{|c|c|c|c|c|c|c|c|c|c|}
\hline \multirow[b]{2}{*}{ Element } & \multirow[b]{2}{*}{$\begin{array}{c}\text { Certified } \\
\text { Value }\end{array}$} & \multicolumn{4}{|c|}{ WDXRFS } & \multicolumn{4}{|c|}{ ICP-OES } \\
\hline & & $\begin{array}{l}\text { Mean } \\
(n=6)\end{array}$ & $\begin{array}{l}\text { Std. } \\
\text { Dev. }\end{array}$ & $\begin{array}{l}\text { CV } \\
(\%)\end{array}$ & $\begin{array}{c}\text { Accuracy } \\
(\%)\end{array}$ & $\begin{array}{l}\text { Mean } \\
(n=6)\end{array}$ & $\begin{array}{l}\text { Std. } \\
\text { Dev. }\end{array}$ & $\begin{array}{l}\text { CV } \\
(\%)\end{array}$ & $\begin{array}{c}\text { Accuracy } \\
(\%)\end{array}$ \\
\hline S (\%) & 1.57 & 1.56 & 0.0103 & 0.661 & 0.64 & 1.54 & 0.015 & 0.95 & 1.91 \\
\hline $\mathrm{V}(\mathrm{ppm})$ & 87 & 86 & 0.8944 & 1.040 & 1.15 & 83 & 1.14 & 1.38 & 4.60 \\
\hline $\mathrm{Cu}(\mathrm{ppm})$ & 44 & 43 & 0.5164 & 1.192 & 2.27 & 42 & 1.58 & 3.76 & 4.55 \\
\hline $\mathrm{Zn}(\mathrm{ppm})$ & 331 & 330 & 0.8944 & 0.271 & 0.30 & 318 & 2.54 & 0.8 & 3.93 \\
\hline Sr (ppm) & 250 & 256 & 0.8165 & 0.325 & 2.40 & 243 & 1.92 & 0.79 & 2.80 \\
\hline Mo (ppm) & 10 & 11 & 0.4082 & 3.656 & 10.00 & 9 & 1.3 & 14.17 & 10.00 \\
\hline Ce (ppm) & 27 & 26 & 0.5477 & 2.148 & 3.70 & 24 & 1.51 & 6.16 & 11.11 \\
\hline $\mathrm{U}^{\mathrm{a}}(\mathrm{ppm})$ & 9.7 & 9 & 0.5477 & 5.216 & 7.22 & 9.8 & 0.84 & 8.54 & 1.03 \\
\hline
\end{tabular}

${ }^{\mathrm{a}}=\mathrm{U}$ by Fluorimetry $\mathrm{n}=$ Number of determinations, Std. Dev. = standard deviation, \%CV $=\mathrm{Coefficient}$ of variation .

Accuracy is the percentage of deviation of the arithmetic mean of a set of six values from the certified value. 


\section{Atomic Spectroscopy \\ 1 Vol. 34(1), Jan./Feb. 2013}

TABLE VI

Analytical Results for Geological Samples Analyzed by WDXRFS, ICP-OES, and FluorimetryTechniques.

\begin{tabular}{|c|c|c|c|c|c|c|c|c|c|c|c|c|c|c|c|c|c|c|c|c|c|c|}
\hline \multirow{2}{*}{$\begin{array}{l}\text { Ele- } \\
\text { ments }\end{array}$} & \multicolumn{2}{|c|}{ AMD-1 } & \multicolumn{2}{|c|}{ AMD-2 } & \multicolumn{2}{|c|}{ AMD-3 } & \multicolumn{2}{|c|}{ AMD-4 } & \multicolumn{2}{|c|}{ AMD-5 } & \multicolumn{2}{|c|}{ AMD-6 } & \multicolumn{2}{|c|}{ AMD-7 } & \multicolumn{2}{|c|}{ AMD-8 } & \multicolumn{2}{|c|}{ AMD-9 } & \multicolumn{2}{|c|}{ AMD-10 } & \multicolumn{2}{|c|}{ AMD-11 } \\
\hline & XRF & ICP & XRF & ICP & XRF & ICP & XRF & ICP & XRF & ICP & XRF & ICP & XRF & ICP & XRF & ICP & XRF & ICP & XRF & ICP & XRF & ICP \\
\hline V & 12 & 10 & 60 & 54 & 79 & 88 & 210 & 200 & 341 & 330 & 229 & 220 & 245 & 238 & 119 & 124 & 50 & 48 & 38 & 32 & 45 & 50 \\
\hline $\mathrm{Cu}$ & 825 & 832 & 1536 & 1548 & 775 & 780 & 222 & 214 & 125 & 132 & 78 & 88 & 185 & 178 & 34 & 36 & 13 & 14 & 11 & 10 & 5476 & 5455 \\
\hline $\mathrm{Zn}$ & 20 & 22 & 16 & 14 & 7 & 6 & 9 & 8 & 9 & 8 & 7 & 8 & 6 & 8 & 10 & 8 & 65 & 60 & 50 & 54 & 155 & 150 \\
\hline $\mathrm{Sr}$ & 247 & 252 & 355 & 350 & 331 & 336 & 385 & 378 & 364 & 372 & 461 & 454 & 435 & 442 & 440 & 432 & 262 & 256 & 216 & 220 & 306 & 301 \\
\hline Mo & 20 & 18 & 60 & 56 & 105 & 100 & 189 & 194 & 341 & 330 & 225 & 230 & 241 & 236 & 124 & 120 & 46 & 48 & 35 & 38 & 42 & 44 \\
\hline $\mathrm{Ce}$ & 34 & 36 & 22 & 24 & 16 & 14 & 32 & 30 & 20 & 18 & 26 & 28 & 27 & 26 & 28 & 30 & 14 & 16 & 14 & 16 & 26 & 24 \\
\hline \multirow[t]{2}{*}{$\mathrm{S}(\%)$} & 5.08 & 4.99 & 0.44 & 0.53 & 0.69 & 0.77 & 0.82 & 0.74 & 0.6 & 0.53 & 0.5 & 0.47 & 0.41 & 0.46 & 0.5 & 0.56 & 0.31 & 0.38 & 0.35 & 0.42 & 0.25 & 0.33 \\
\hline & XRF & Fluori & XRF & Fluori & XRF & Fluori & XRF $\mathrm{F}$ & Fluori & XRF & Fluori & XRF & Fluori & XRF & Fluori & XRF & Fluori & XRF & Fluori & XRF & Fluori & XRF & Fluori \\
\hline $\mathrm{U}$ & 14 & 12 & 149 & 142 & 594 & 586 & 225 & 234 & 415 & 408 & 645 & 638 & 340 & 336 & 445 & 440 & 39 & 42 & 14 & 16 & 761 & 750 \\
\hline
\end{tabular}

XRF: WDXRF; ICP: ICP-OES; Fluori: Fluorimetry.

Except for Sulfur, all other elements concentration mentioned here in ppm.

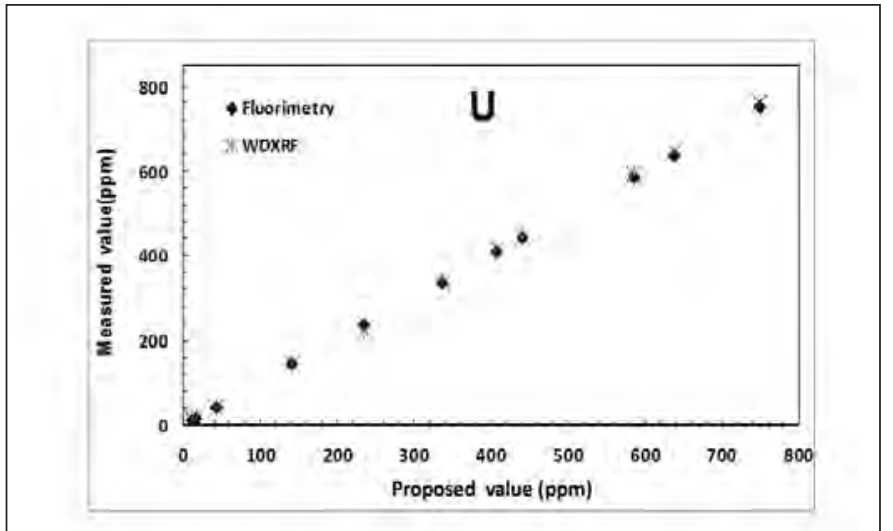

Fig. 2 Comparison of values obtained by Fluorimetry and WDXRFS.

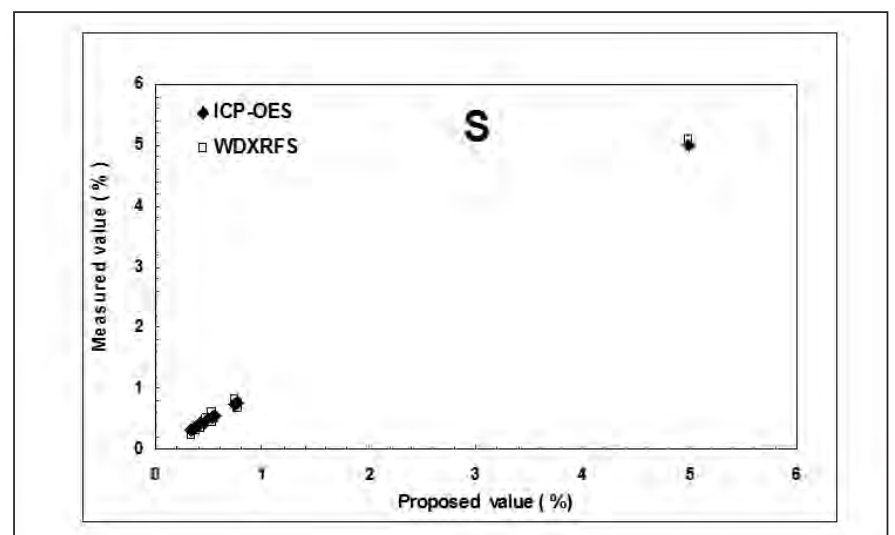

Fig. 3 Comparison of values obtained by ICP-OES and WDXRFS
The analysis of rock samples by ICP-OES, AAS, and fluorimetry involves laborious sample dissolution, separation, and various analysis steps. However, the sample preparation step for WDXRF is minimal and the technique is very fast in comparison to the other complementary techniques mentioned. About 30 samples can be analyzed by WDXRFS within eight hours and thus provide quick feedback to the uranium exploration project.
The XRFS methods of analysis do not require chemical preparation of the samples in a clean room which involves HF digestions. XRF spectrometers are simple to operate for routine analyses and can work unattended overnight and for long periods of time. The XRF method is non-destructive and, apart from the simple sample preparation, the standards so prepared can be preserved and reused even over a period of many years.
In the present study, the powder pelletization sample preparation technique has been adopted in place of the fusion bead technique by using lithium tetraborate/metaborate at $1100^{\circ} \mathrm{C}$, and the loss of elemental sulfur by volatilization during fusion at elevated temperatures has been overcome. 